\title{
OPTIMIZATION OF TERMINAL SERVICEABILITY BASED ON CHAOTIC GA-BASED METHOD
}

\author{
C.H. Wu ${ }^{* 1}$, Polly P.L. Leung ${ }^{2}$, N. Dong ${ }^{* 3}$, G.T.S. Ho ${ }^{4}$, C.K. Kwong ${ }^{5}$, W.H. Ip ${ }^{6}$ \\ ${ }^{1,4}$ Department of Supply Chain and Information Management, The Hang Seng University of Hong Kong, China \\ ${ }^{2,5,6}$ Department of Industrial and Systems Engineering, The Hong Kong Polytechnic University, Hong Kong, China \\ ${ }^{3}$ School of Electrical Engineering and Information Engineering, Tianjin University, Tianjin 300072, China \\ ${ }^{6}$ Department of Mechanical Engineering, University of Saskatchewan, Saskatoon, Canada
}

Email: jackwu@ieee.org ${ }^{1}$ (corresponding author),po-ling-polly.leung@connect.polyu.hk², dongna@tju.edu.cn ${ }^{3}$ (corresponding author),georgeho@hsu.edu.hk ${ }^{4}$, c.k.kwong@polyu.edu.hk ${ }^{5}$,wh.ip@polyu.edu.hk ${ }^{6}$

DOI: https://doi.org/10.22452/mjcs.vol32no1.5

\begin{abstract}
Minimizing cargo handling time and waiting time of ship are some of the most critical tasks for terminal operators during berth allocation planning. An efficient and effective berth allocation planning approach is not only significant for improving a terminal's productivity but worth even more in enhancing terminal serviceability. As berths are no longer leased by specific ship lines or ship companies in the majority of terminals, ships of various sizes and various cargo handling volume at a particular terminal of call are competing for the same berth for handling. As a result, there are always concerns from both terminal operators and ship companies regarding the service priority. This research contributes to deal with the dilemma terminal operators encountered in balancing service priority and terminal productivity maximization during berth allocation. This research deals with berth allocation problem which treats calling ships at various service priorities with physical constraints. The problem encountered is to determine how to cope with various ships with various attributes in the system, and the objective is to minimize the total service time of a set of given calling ships through proper berth allocation. This research adopts a chaotic genetic algorithm-based method to deal with the problem. The new formulation and method have been proposed and results obtained have been compared with the existing one in literature. The results show the improved feasibility of the proposed formulation and improved convergence speed of the proposed method over the existing one. Also, higher terminal serviceability is indicated.
\end{abstract}

Keywords: Chaotic Genetic Algorithms (CGA), berth allocation, service priority, terminal serviceability.

\subsection{INTRODUCTION}

Prior to a ship's arrival at the terminal, particular quay space or a berth has to be allocated to it with considerations to the issues involved such as the estimated arrival time of the ship, physical relationship between the berth and the ship as well as service priority. Berth allocation plays an important role in determining the terminal productivity as the handling time for a specific ship is not necessarily the same at every berth. Concurrently, utilization of costly terminal infrastructure determined by berth allocation planning plays an important role in enhancing terminal serviceability. The serviceability of a berth is considered as a degree to which the servicing of a ship can be accomplished with given resources and within a specified timeframe. A good berth allocation scheme can help to minimize the total service time of all ships and thus enable the terminal to serve more ships. Consequently, the number of containers being handled is increased so as to increase terminal profits.

The berth allocation problem (BAP) consists of 2 components, which are the assignment of quay space and the assignment of service time (or service order) to calling ships [1]. When combined, the berth allocation helps to assign and schedule incoming ships to berth for cargo handling. The assignment of quay space to calling ships refers to the allocation of ships to the proper quay locations based on the berth since the entire quay is usually partitioned into several berths for managerial purposes. Ships of various sizes arrive at the terminal at the different time and bearing different container handling volume. The highly dynamic environment and diverse ship's attribute make it difficult for terminal operators to assign ships to berths in a balanced way. There are numerous ways to assign ships to berths as illustrated in Fig. 1. As shown in the graph, there will be 24 (4!) possible combinations even it is a simplified case with 4 calling ships and 4 berths only. 


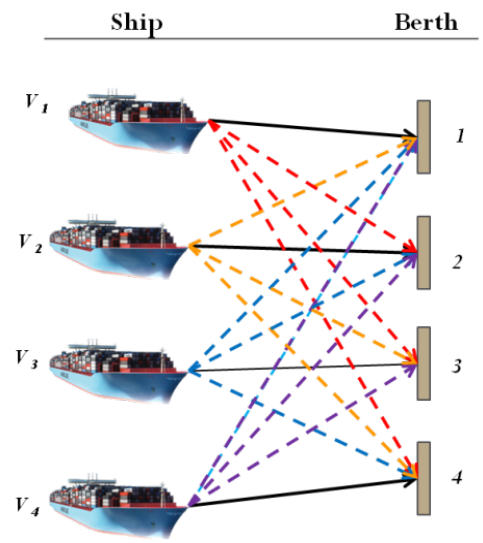

Fig. 1: Assignment of quay space to calling ships

Other than the assignments of quay space to calling ships, the assignments of service time (or service order) to calling ships is another indispensable component of berth allocation. As there is no longer berth leased by specific ship lines or shipping companies in the majority of terminals, ships of various sizes and various cargo handling volumes at a particular terminal of call are competing for the same berth, as demonstrated in Fig. 2. As a result, there are always concerns from both terminal operators and shipping companies regarding the service order and service priority.

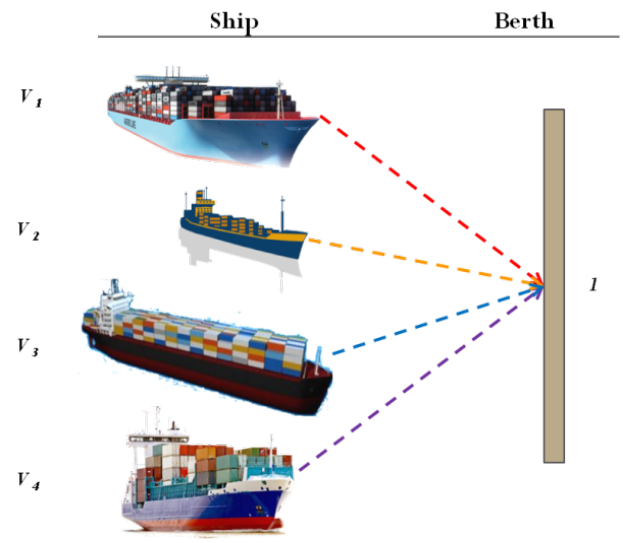

Fig. 2: Assignment of service time (or service order) to calling ships

This research describes an adoption of Chaotic Genetic Algorithm (CGA)-based method in solving the Berth Allocation Problem with Priority Consideration (PBAP). Berth allocation is one of the major operative planning modules which is not only closely related to the efficiency of cargo handling but also able to become a competitive advantage of terminals $[2,3]$ or even considered as the fundamentals part of terminal operations [4-6]. This research is also motivated by the desire of terminal operators for enhanced terminal serviceability through optimally assigning and scheduling ships to berth, taking into account the dilemma they encountered in balancing service priorities and terminal productivity maximization during berth allocation. Although there are existing formulations for PBAP in literature, it considers no physical constraints, and thus, lowerings its applicability.

This research addresses the PBAP and focuses on developing an optimal solution to deal with it. This research takes into account ships that have already arrived as well as those that have not arrived at the time of planning but will arrive at some moment during the planning phase. The aim of this research is to improve the existing formulation of PBAP and develop a feasible CGA-based method for PBAP. The proposed formulation and method are compared with literature in order to examine how to differ in solution quality. The proposed formulation and method are developed for the sake of terminal serviceability maximization, and ultimately maximizing a berth's profitability.

The paper is divided into the following sections. Section 2 is a brief review of the background and previous work. Section 3 presents the proposed formulation of PBAP with physical constraints. Section 4 presents the use of CGA- 
based method in solving the proposed PBAP formulation. Section 5 reports the results of experimental simulations in solving the proposed formulation and compares the performance between formulations and methods in literature and the proposed one, and Section 6 is the conclusion.

\subsection{BACKGROUND AND PREVIOUS WORK}

As global trade increases, further and a substantial increase in the use of containers for maritime transportation has been predicted. These give rise to the interest of container terminal logistics in literature. Many papers have been published dealing with issues concerning container shipping industry such as planning, scheduling, operation, and management issues [7-14]. Generally, container terminal operations start when the calling ships arrive at the terminal with pre-known arrival time and they will then be assigned to a berth at particular quay location at particular sequence according to the berthing plan. After being assigned to the berth, containers will be discharged with the help of quay cranes (QC), and the discharged containers will be transported by internal trucks (IT) to the planned location of the yard for stacking and temporary storage $[8,12,15]$.

Berth allocation refers to the assignment of berths and service time (or service order) to incoming ships for cargo handling before their arrival [1,16-21]. Berth allocation needs to take into consideration the arrival time of ships, physical constraints (such as ship length and berth length). Berth allocation plays an important role in determining the terminal productivity as the length of waiting time that calling ships to wait for an idle berth and handling time for a specific ship may depend on the berth to be handled [17, 20, 22-24]. A good berth allocation scheme can be measured in terms of cost saving [25], total waiting time minimization, total handling time minimization or even total service time minimization $[7,22,26,27]$.

\subsection{Service Priority Consideration}

As berths are no longer leased by specific ship lines or ship companies in the majority of terminals, ships of various sizes and various cargo handling volumes at a particular terminal of call are competing for the same berth for handling. As a result, there are always concerns from both terminal operators and ship companies regarding the service priority $[5,6]$. While scheduling ships to quay location (or particularly to berth), only several works on BAP are extended with service priority[21]. Before the introduction of the concept of priority, the previous researches have dealt with the assignment of service time to ships using a wide variety of ways. One of the earliest papers that explicitly dealt with service order was written by Lai and Shih [28]. Motivated by the requirement of more efficient berth usage at the Hong Kong International Terminals Limited (HIT), they proposed heuristic algorithms for BAP. In their paper, the 'First-Come-First-Serve (FCFS)' scheduling strategy was assumed [28]. Later on, Imai et al. also studied the BAP at commercial terminals, where most service queues were traditionally processed on a FCFS basis [29]. They concluded the work with an important idea that the optimal berth allocation should not consider the FCFS heuristic for high terminal throughput and efficiency. On the other hand, they were also aware of the possible dissatisfaction resulted among shipping companies concerning the service order.

To cope with the problem associated with dissatisfaction regarding service order, as well as to balance it with terminal productivity, a few researchers have tackled BAP with priority consideration $[19,22,24]$. Even though service priority has been incorporated in BAP in a few studies, there are still arguments for the choice of priority. At the same time, terminal operators have different preferences regarding the service priority. For example, it was reported that most of the Japanese terminals preferred ships with larger container volume being served first while ships with smaller container volume were favored in Dalian container terminal of China [5, 6, 22, 30-32] Ursavas [32] extended the work of BAP on priority considerations by proposing a decision support system for determining priority controls based on simulation optimization.

Generally, service priority can be divided into two groups, which are hard priority and soft priority. Hard priorities refer to those priorities explicitly assigned to the calling ships. Examples of hard priorities include First-ComeFirst-Served (arrival time-based) and ships with higher handling volume first (cargo handling volume-based) [5, 6, $22,30,31]$. The term 'soft priority' appeared first in 2003 that researchers defined soft priority as the priorities associated with ships which are not explicitly defined in problem formulation; instead, the priorities are being evaluated based on the resultant objective function value [22].

Berth allocation that takes priority consideration into account is of high value to terminal operators to enhance terminal serviceability. It is not a must to give priorities to ships in the formulation explicitly for ship differentiation since the choice of priorities should be terminal-dependent and scenario-oriented. As a result, those BAP 
approaches with hard priorities in literature have limited usage. This gives rise to the argument that win-win situations for shipping companies and container terminals are more likely to be achieved when BAP is solved with soft priorities consideration. However, to the best of our knowledge, only three studies have solved BAP with soft priorities. Imai et al., in their work presented several arguments and examples for differentiating the service order of ships ' [22]. This was the first paper dealing with soft priorities, where ships were associated with differentiated weight. Realizing the need of satisfying both ship companies and terminal operators [22], another research team has considered the BAP as a multi-objective optimization problem to concurrently minimize the makespan of the terminal, the waiting time of ships and deviation from a predetermined berthing schedule [19]. The formulation was suggested to allow flexibility of terminal operators in assigning service priority to ships, and also flexibility in scheduling ships to berth. The latest study which incorporated soft priority into consideration was conducted by Lalla-Ruiz et al. [24]. In their paper, they addressed the PBAP under time-dependent limitations by considering a multi-period planning horizon, formulating an alternative mathematical model and proposing an optimization model.

Despite the documented importance of dealing with the dilemma in balancing service priorities and terminal productivity maximization during berth allocation, a limited number of studies have considered service priority. Although there exist formulations for PBAP in literature, the majority of them considered only the hard priorities explicitly assigned to the calling ships and caused dissatisfaction to ship companies and failed to balance service order with terminal productivity. To our knowledge, only three existing studies have considered soft priorities; however, they considered no physical constraints and lowered their applicability. Addressing insufficient research works taking soft priority into account during berth allocation, and the limitation of the existing formulations of PBAP, the existing dynamic formulation with soft priorities is proposed in this research to take additional physical constraints into account as the evaluation criteria to ensure the formulation to be applicable while serviceable to terminals.

\subsection{Existing Approaches for BAP and PBAP}

BAP has been widely studied by researchers [25]. There are a lot of approaches used for dealing with BAP and PBAP. BAP is widely known as NP-hard [1, 5, 6, 22, 33]. Zhen et al. [1] stated in his paper that "the deterministic BAP is NP-hard". Indeed, not only the deterministic BAP has been proven to be "non-deterministic polynomialtime hard (NP-hard)", it has been proven and stated by many researchers that BAP is NP-hard [5, 6, 22, 33]. Although examination and proof of NP-hard problems are beyond the scope of this research, it is believed that the BAP is NP-hard as mentioned and concluded by the previous researches.

Being a NP-hard problem, there will be no efficient exact algorithm for the problem using any existing way, and heavy computational burden is required to solve the problem, especially for realistic large-scale problem [27]. Therefore, it is a common practice to obtain near-optimal solution for NP-hard problems using evolutionary methods or heuristics [22, 26, 27, 34, 35].

Park and Kim [34] solved the BAP with crane assignment using Lagrangean relaxation based heuristic and dynamic programming. Cheong and Tan [36] examined the BAP in multi-user terminals (MUTs) with the objectives of minimizing total service time of ships and total delay time in ship departure simultaneously. To solve such a multiobjective optimization problem, they have presented and applied a Multi-objective Multi-colony Ant Algorithm (MOMCAA). Golias [37] and Karafa et al. [35] formulated the BAP as a bi-objective mixed integer programming problem to minimize the total service time of all calling ships while minimizing the derivation of the berth schedule. Golias [37] solved the problem with a combination of an exact algorithm, a GA-based heuristic and a Monte Carlo simulation. Karafa et al. [35] solved the BAP with stochastic ship handling time with a combination of an evolutionary algorithm-based heuristic and a simulation-based Pareto front-pruning heuristic. Lalla-Ruiz et al. [38] addressed the discrete case of the BAP with dynamic ship arrival time, and proposed a hybrid metaheuristic that combines Tabu Search with Path Relinking. Lin et al. [27] studied BAP with dynamic ship arrival time. They aimed to minimize the total service time of all calling ships by using an iterated greedy algorithm. Tsai et al. [39] solved the BAP for a public berth with the objective of minimizing the total waiting time of calling ships using a wharf-based GA.

Among the existing algorithms, modern heuristics based on artificial intelligence (AI) techniques such as GA are widely employed to approximately optimize the solution. GA is getting more popular among and recognized by researchers that it is suitable and relatively efficient when dealing with NP-hard problems. According to Lau and Zhao [40], "although GA is a heuristic method and cannot guarantee optimal solutions in general, it is relatively 
efficient in solving NP-hard problems". Theofanis et al. [41] stated in their paper that "genetic algorithm based heuristics are very popular as a BAP solution approach".

Regarding the only three existing studies considering soft priority we have identified, Imai et al. [22] have tried to obtain a Lagrangian relaxation formulation of the PBAP; however, the PBAP has become a "quadratic assignment problem" (QAP) which is still an NP-hard problem. They have therefore employed a Genetic Algorithm (GA)based heuristic to facilitate the solution procedures. Cheong et al. [19] have utilized and integrated local search heuristic, a hybrid solution decoding scheme, and an optimal berth insertion procedure as a multi-objective evolutionary algorithm (MOEA) to solve the multi-objective PBAP. Addressing the BAP under time-dependent limitations, the latest study which incorporated soft priority into consideration, Lalla-Ruiz et al. [24] proposed an alternative mathematical model and solved it using a Generalized Set-Partitioning Approach.

To solve the difficulties and NP-hard PBAP within short computational time while maintaining the quality of solution obtained, GA-based method is a reasonable approach. Also, this research is primarily based on the study of Imai et al. [22], which employed GA as well. Furthermore, several studies have successfully applied CGA-based methods for overcoming the problems of premature convergence and the slow reaching of global optimum in optimization problems and scheduling problems. Yuan et al. [42] developed a hybrid CGA for the short-term hydro system scheduling problem with convergence speed increased and premature overcame. Hong et al. [43] addressed the tourism demand forecasting problem by presenting a support vector regression (SVR) model with a CGA. Their proposed CGA was proved to be effective in overcoming premature local optimum during genetic parameters determination. The work by Hong et al. [44] presented a CGA for solving the SVR-based electric load forecasting problem. The numerical example showed that this algorithm improved the premature convergence of GA. In this regard, we proposed a CGA-based method for addressing the PBAP, which is believed to be able to obtain optimal solutions by increasing convergence speed and overcoming premature local optimum.

\subsection{Existing Problem Formulation of PBAP}

In this section, the assumptions, notations, objective function and problem constraints of the existing formulation are summarized. The assumptions included can be found in Table 1.

Table 1: Assumptions of the problem [22]

\begin{tabular}{|l|}
\hline It is a multi-user terminal (MUT) \\
\hline The only long wharf is virtually divided into several berths \\
\hline The assignment of ships to quay space is based on berths \\
\hline Each berth can serve up to 1 ship at any time despite the size, especially ship length, of the ship \\
\hline There are no physical constraints \\
\hline Ship arrival has dynamic nature \\
\hline Ships are banned from moving until their departure \\
\hline
\end{tabular}

A PBAP as shown in Fig. 3 is to be studied. The problem consists of $(J)$ berth, and a set of calling ships, indexing from $V_{I}$ to $V_{I}$. The notations used to describe the problem studied can be found in Table 2 . 


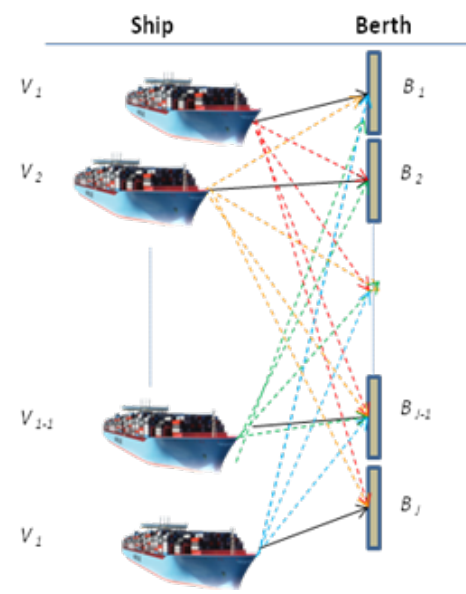

Fig. 3: BAP model with $J$ discrete berths and $I$ ships

Table 2: Notations of the problem [22]

\begin{tabular}{|l|l|}
\hline Notations of problems - General parameters \\
\hline Notation & Meaning \\
\hline$i$ & Index for calling ships, $i=(1, \ldots \ldots, I) \in V$ the set of calling ships \\
\hline$j$ & Index for berth, $j=(1, \ldots \ldots, J) \in B$ the set of berths \\
\hline$k$ & Index for service orders, $k=(1, \ldots \ldots, I) \in T$ the set of service orders \\
\hline$m$ & Index for calling ships, $m=(1, \ldots \ldots, I) \in Q_{k}$ the subset of $T$ such that $Q_{k}=\{q \mid q<k \in T\}$ \\
\hline$C_{i}$ & Container handling volume of ship $i$ \\
\hline$A_{i}$ & Arrival time of calling ships $i$ \\
\hline$P_{j}$ & Time when berth $j$ becomes idle for the planning horizon \\
\hline$S_{i}$ & Subset of ships with $A_{i} \geq P_{j}$ \\
\hline$H_{i}$ & Handling time of calling ship $i$ \\
\hline$w_{i}$ & Weight for ship $i$ \\
\hline Notations of problems - Decision variables \\
\hline Notation & Meaning \\
\hline$x_{i j k}$ & Set to 1 if ship $i$ is handled as the $k$ th ship at berth $j ; 0$ otherwise \\
\hline Notations of problems - Variable \\
\hline Notation & Meaning \\
\hline$y_{i j k}$ & $\begin{array}{l}\text { Idle time of berth } j \text { between arrival of the } k^{\text {th }} \text { ship and departure of the }(k-1)^{\text {th }} \text { ship } \\
\text { when ship } i \text { is handled as the } k \text { th ship at berth } j\end{array}$ \\
\hline
\end{tabular}

The objective is to minimize the total service time, which is the sum of handling time and waiting time, of all calling ships. The decision variable is $x_{i j k}$. With the solution of $x_{i j k}$, the total service time can be calculated. The objective function is shown in Equation (1). The problem constraints stated in the current problem formulation can be found in Table 3. 


$$
\sum_{i \in V} \sum_{j \in B} \sum_{k \in T}\left\{H_{i}+P_{j}-A_{i}+\sum_{i \in V} \sum_{m \in Q_{k}} H_{i} x_{i j m}\right\} w_{i} x_{i j k}+\sum_{i \in S_{i}} \sum_{j \in B} \sum_{k \in T}\left\{y_{i j k}+\sum_{i \in V} \sum_{m \in Q_{k}} y_{i j m}\right\} w_{i}
$$

Where

\begin{tabular}{|ll|l|}
\hline$x_{i j k} \in\{0,1\}$ & $\forall i \in V_{o j} \in B_{s} k \in T$ & $(2)$ \\
\hline$y_{i j k} \geq 0$ & $\forall i \in V_{o} j \in B_{s} k \in T$ & (3) \\
\hline
\end{tabular}

Table 3: Problem constraints

\begin{tabular}{|c|c|c|}
\hline$\sum_{j \in B} \sum_{k \in T} x_{i j k}=1$ & $\forall i \in V$ & (4) \\
\hline$\sum_{i \in V} x_{i j k} \leq 1$ & $j \in B_{s} k \in T$ & (5) \\
\hline$\sum_{i \in V} \sum_{m \in Q_{k}}\left(H_{i} x_{i j m}+y_{i j m}\right)+y_{i j k}-\left(A_{i}-P_{j}\right) x_{i j k} \geq 0$ & $\forall i \in S_{i \mathbb{i}} j \in B_{x} k \in T$ & (6) \\
\hline
\end{tabular}

Considering a ship being served, the total service time of any particular berth is the sum of 1) ship handling time, and 2) the product of the length of potential service queue following the ship and the handling time. The first term of the objective function (1) is the total service time of ships weighted by priority $w_{i}$ without considering time gap between two adjoining ships in case of berth idling that results from the late arrival of the ship. The second term takes the time gap into consideration. Constraint set (4) ensures that each of the calling ships must be served at one of the berths in any service order. Constraint set (5) ensures that no more than 1 ship can be served by the same berth at the same time. Constraint set (6) ensures that ship can only be served after its arrival.

\subsection{PROPOSED FORMULATION OF PBAP WITH PHYSICAL CONSTRAINT}

In this section, physical constraints are incorporated into the existing formulation of PBAP which has been mentioned in the previous section. A new formulation of PBAP with physical constraints will be given and discussed in detail in order to deal with calling ships with various ship lengths and berths with various berth lengths.

There are arguments for the previous work in the formulation of PBAP which treats ships without physical constraints concerning its feasibility and applicability to be applied in the real-world situation. Therefore, for the modified model which takes into consideration the relationship between ship length and berth length, some of the assumptions made for the PBAP without physical constraints have to be modified. The updated assumptions are summarized in Table 4, where those additional assumptions take into account and enforce the physical constraints relating to berth length and ship length and can be found in literature which took physical constraints into account $[16,45]$.

Table 4: Modifications to assumptions

\begin{tabular}{|l|l|}
\hline Assumptions abolished & Assumptions added \\
\hline $\begin{array}{l}\text { Each berth can serve up to 1 ship at any time despite } \\
\text { the size, especially ship length, of the ship }\end{array}$ & $\begin{array}{l}\text { Inter-ship clearance distance is included in the ship } \\
\text { length when two ships are assigned to adjacent berths }\end{array}$ \\
\hline There are no physical constraints & $\begin{array}{l}\text { There is a physical constraint restricting the maximum } \\
\text { ship length each berth can serve }\end{array}$ \\
\hline & $\begin{array}{l}\text { Each calling ship can be served by any of the suitable } \\
\text { berths which can physically accommodate it with the } \\
\text { same handling time }\left(H_{i}\right)\end{array}$ \\
\hline
\end{tabular}

There is a set of own attributes for each calling ship, such as ship length $(L)$, arrival time $(A)$ and cargo handling volume $(C)$, and there is also a set of own attributes for each berth, and especially berth length $(R)$. The notations added to describe the problem studied under the proposed formulation can be found in Table 5. 
Table 5: Notations of problems - General parameters

\begin{tabular}{|l|l|}
\hline Notation & Meaning \\
\hline$R_{j}$ & Berth length of berth $j$ \\
\hline$L_{i}$ & Ship length of ship $i$ \\
\hline
\end{tabular}

It is recalled that the weight for ship $i\left(w_{i}\right)$ is a softly defined-priority assigned to ship $i$. The weight is evaluated by the resultant weighted service time for each calling ship. It is designed in a way that any type of weight, such as a function of ship's cargo handling volume, can be added to individual calling ships to differentiate their priorities. The formulation of PBAP is subject to the additional constraint (7):

\begin{tabular}{|l|l|l|}
\hline$L_{i} \leq R_{j}$ & $\forall i \in V, j \in B$ & (7) \\
\hline
\end{tabular}

Constraint set (7) is added to the original formulation to ensure that all ships must be berthed within the berth length where it is assigned to. Similar constraint which ensures ships must be handled at berths with acceptable physical conditions can be found in the existing literature [16, 20, 46, 47].

The same objective, i.e., minimization of total service time of all calling ships, is used for PBAP with physical constraints. The minimization of total service time enables terminal operators to serve more ships and handle more cargos and yield higher serviceability. Also, as far as satisfaction of shipping companies can be maximized when total service time is minimized, the maximized satisfaction will encourage an establishment of a long-term relationship between terminal operators and shipping companies, which in other words maximize terminal serviceability in the long term. Moreover, total service time is used as the evaluation criteria for terminal productivity in the literature [22]. All these support the usage of total service time as the evaluation criteria for terminal serviceability in this research. It is reminded that binary value is used as the decision variable in this research for both formulations with and without physical constraints rather than using the actual unit time for indexing berthing sequences. It is to avoid handling incredibly a huge amount of decision variables while ensuring consecutive service for calling ships. Similar usage of binary value as the decision variable can be found in the previous work $[5,6,22,48]$.

\subsection{ADOPTION OF CHAOTIC GA-BASED METHOD}

The size of population in the CGA-based method is set to 30, which is the same as the setting in the literature [22].

\subsection{Encoding of Chromosome}

The chromosomes are represented as character strings to work with scheduling order of ship-to-berth assignment instead of directly with berthing times. The chromosomes consist of $(I+J-1)$ genes. The service queue of each berth is separated with zero, and the scheduling order is arranged from the highest on the left to the lowest on the right. An example of a chromosome encoding for a three-berth thirteen-ship PBAP is shown in Fig. 4. In the example, the chromosome consists of $15(13+3-1)$ genes. Ships 1,3 and 5 are assigned to berth 1 and ship 1 is scheduled at berth 1 before ships 3 and 5 .

\begin{tabular}{|c|c|c|c|c|c|c|c|c|c|c|c|c|c|c|c|}
\hline GENE: & SHII & -13, & & & & & & & & & & & & & \\
\hline (CELL) & 1 & 2 & 3 & 4 & 5 & 6 & 7 & 8 & 9 & 10 & 11 & 12 & 13 & 14 & 15 \\
\hline CHROMOSOME & \begin{tabular}{|l|l}
1 \\
\end{tabular} & 3 & 5 & 0 & 9 & 10 & 6 & 13 & 4 & 0 & 12 & 2 & 11 & 8 & 7 \\
\hline BERTH & 1 & 1 & 1 & $\uparrow$ & 2 & 2 & 2 & 2 & 2 & $\uparrow$ & 3 & 3 & 3 & 3 & 3 \\
\hline ORDER OF SERVICE & 1 & 2 & 3 & & 1 & 2 & 3 & 4 & 5 & & 1 & 2 & 3 & 4 & 5 \\
\hline & & & ind & & & & & & ind & ry of & bertl & & & & \\
\hline
\end{tabular}

Fig. 4: Chromosome representation

\subsection{Chaotic Initialization}


In order to improve the whole performance in the global search, the notion of chaos into the initialization and the mutation process is introduced. Since it gives the uniform distribution function in the interval [0.0:1.0], the tent map shows outstanding advantages and higher iterative speed than the logistic map [49]. In this research, the tent map is used to generate chaos variables. The tent map is defined by:

$z_{n+1}=\mu\left(1-2\left|z_{n}-0.5\right|\right), 0 \leq z_{0} \leq 1, n=0,1,2 \ldots$

where $\mu \epsilon(0,1)$ is the bifurcation parameter. Specifically, when $\mu=1$, the tent map exhibits entirely chaotic dynamics and ergodicity in the interval [0.0:1.0]. Firstly, we give a brief review of the traditional process of chaotic initialization:

Using the tent map $(\mu=1)$ to generate the chaos variables and rewriting Equation (8), gives:

$$
z_{\beta}^{(\alpha+1)}=\mu\left(1-2\left|z_{\beta}^{(\alpha)}-0.5\right|\right), \beta=1,2, \ldots, D
$$

where $z_{\beta}$ denotes the $\beta^{\text {th }}$ chaos variable, and $\alpha$ denotes the chaos iteration number. Set $\alpha=0$ and generate $\mathrm{D}$ chaos variables by Equation (9). After that, let $\alpha=1,2, \ldots, \gamma$ in turn and generate the initial population. Then, the above chaos variable $z_{\beta}^{(\alpha)}, \alpha=1,2, \ldots, \gamma$, will be mapped into the search range of the decision variable:

$\varphi_{\alpha \beta}=\varphi_{\min , \beta}+z_{\beta}^{(\alpha)}\left(\varphi_{\max , \beta}-\varphi_{\min , \beta}\right), \beta=1,2, \ldots, D$

Defining:

$\varphi_{\alpha}=\varphi_{\alpha 1}, \varphi_{\alpha 2, \ldots, \ldots} \varphi_{\alpha D}, \alpha=1,2, \ldots, \gamma$

and then, the chaos initialized population can be obtained.

In our proposed CGA-based method, each chromosome consists of $(I+J-1)$ genes, which include I indexes of the ships and $(J-1)$ zeros. For this case, the scheme of Chaotic Selection is proposed, which includes the following steps:

$>$ Firstly, store the $(I+J-1)$ items (I indexes of the ships and $(J-1)$ zeros) in a matrix.

Then, generate one chaos variable $z$ by Equation (9).

$>$ Map the chaos variable into the range of the decision variable, which is $[1, I+J-1]$ in our case, and get the variable $\varphi$ by Equation (10).

$>$ At last, get the round value of $\varphi$, use it as the index to get the corresponding value in the previous matrix in the first step, and complete the Chaotic Selection for once.

Using the above Chaotic Selection scheme, the chaotic initialization in this research can be described as follows: For each chromosome, fill in the genes from 1 to $(I+J-1)$ one by one. For each gene, do the Chaotic Selection once and generate one round number ranging in $[1, I+J-1]$, then use the number as index and get the corresponding value from the matrix that stores the ships' indexes and zeros, and at last, assign the value to the corresponding gene and then go to the next one until the end. For each gene, if the ship's index exists in the same chromosome, or if its adjacent gene is also a 'zero', then, the Chaotic Selection will be repeated until getting a suitable value. By repeating the above steps for all the $N$ chromosomes ( $N$ is the population size), the whole chaotic initialized population is generated.

\subsection{Validation on Individual's Feasibility and Evaluation}

In a chromosome, ships cannot always be served at the assigned berth due to the physical constraints. It is important to notice that there will be validation to check the feasibility of every individual chromosome in the initial population and after every genetic operation using the constraints described and discussed in Section 3 . If it is a 
feasible chromosome, it will be kept in the pool; otherwise, it will be repaired through the chromosome repair operations described in the corresponding section of genetic operation.

The performance of individual chromosome is evaluated by the value of the objective function in the mathematical model described in Section 2.3. The PBAP is a minimization problem. Imai et al. [22] conducted tests with the functions and found sigmoid function to be better in evaluating PBAP which can avoid "extremely good fitness value among solutions obtained where there is no significant difference between them in the objective function value". The fitness function of PBAP is defined by Equation (12) as follows:

$$
\text { Fitness value of chromosome }=\frac{1}{1+\exp \left(\frac{\text { Objective function value }}{10000}\right)}
$$

\subsection{Formation of Mating Pool}

As usual, the number of chromosomes in the mating pool is the same as that in the initial population. The chromosomes are selected by the Chaotic Selection scheme, which is similar as in Section 4.2, just changing the decision range into $[1, N]$, where $N$ is the population size and the corresponding decision variable is the chromosome's index. To preserve the best chromosome(s), the elitist strategy, which is one of the most common strategies used for mating pool formation, is adopted in this research. In the mating pool, the chromosome having the lowest fitness value will be replaced by the stored best chromosome, which means the one with the highest fitness value, found so far during evolution.

\subsection{Crossover Operation}

Crossover is performed to introduce new chromosomes by exchanging genes of the current chromosome (i.e., parent chromosome) in the mating pool. In each pair of mating chromosomes, a pre-defined number of genes will be selected using the Chaotic Selection scheme (explained in Section 4.2), except for gene with gene value ' 0 ', according to the crossover probability, or the so-called 'crossover-rate' (CR). Theoretically, the number of genes undergo crossover is calculated as $\mathrm{V}^{*} \mathrm{CR}$, where $\mathrm{V}$ is the number of calling ships need to be assigned under PBAP. For example, if the CR is $0.1, \mathrm{~V}$ is 10 , and the crossover point is the one depicted in Fig. 5, the gene (10) from Parent B will replace the one in Parent A, and Offspring A inherits the remaining genes of Parent A. To deal with the redundant or missing ship problem, which is infeasible solution in terms of constraints (4) and/or (5), chromosome repair will be performed and additional interchanges of genes might be required. That is, the gene with the same ship ID with the crossover added-in one will be replaced by the missing ship ID, which is initially in the parent, while ensuring physical constraint is met. For example, the gene (10) is a duplicate of the crossover addedin gene (10) while gene (8) is missing. Therefore, the duplicated gene (10) in Intermediate Offspring A will be replaced by the gene $(8)$.

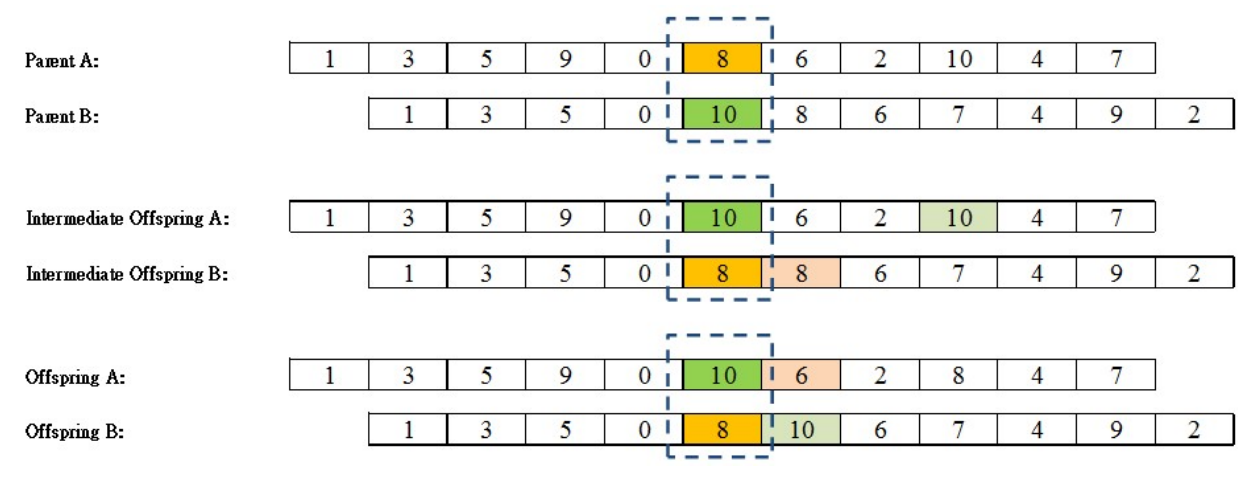

Fig. 5: Sample of the crossover operation

Note that the genes at the crossover point(s) will never change again as long as constraints, especially the physical constraints, are met. Also, the gene with gene value ' 0 ' will not be selected for crossover operation and the crossover point is determined by the composite of 'crossover berth' and 'crossover order' to avoid extreme changes in ship-to-berth assignment. The example illustrated in Fig. 6 shows the destructive high level of chromosome disruption which can be avoided using the crossover mechanism mentioned above. 


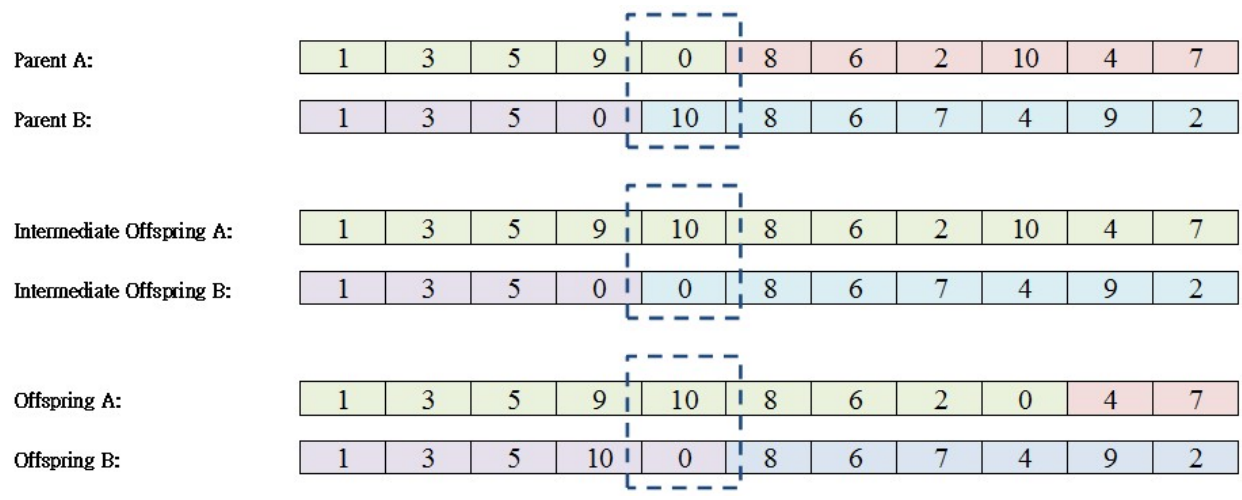

Fig. 6: Disruptive crossover mechanism avoided in this research

Chromosome repair is also needed in case the infeasible solution is generated in terms of constraint (7). In this research, if a ship cannot be served by the assigned berth due to physical constraints, it will be inserted at the end of the service queue of the next berth repeatedly until it is assigned to a berth which can physically accommodate it. For example, if ship 8 cannot be handled at berth 1 as shown in Fig. 7, chromosome repair will be performed, and it will be inserted into berth 2 as the last ship as shown in Fig. 8.

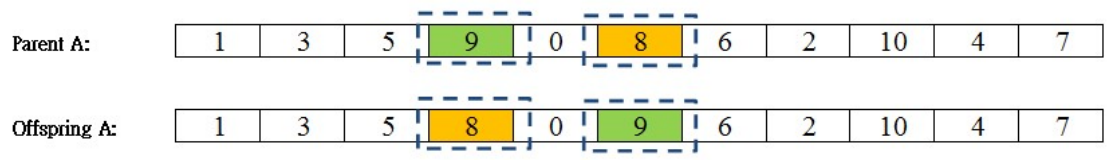

Fig. 7: Example of crossover operation that needs chromosome repair

Parent A:

\begin{tabular}{|l|l|l|l|l|l|l|l|l|l|l|}
\hline 1 & 3 & 5 & 9 & 0 & 8 & 6 & 2 & 10 & 4 & 7 \\
\hline
\end{tabular}

Intermediate Offspring A:

\begin{tabular}{|l|l|l|l|l|l|l|l|l|l|l|}
\hline 1 & 3 & 5 & 8 & 0 & 9 & 6 & 2 & 10 & 4 & 7 \\
\hline
\end{tabular}

Offsping A:

\begin{tabular}{|l|l|l|l|l|l|l|l|l|l|c|}
\hline 1 & 3 & 5 & 0 & 9 & 6 & 2 & 10 & 4 & 7 & 8 \\
\hline
\end{tabular}

Fig. 8: Sample of crossover operation with chromosome repair

\subsection{Mutation by Chaotic Re-Initialization}

Here, unlike Simple GA (SGA), in the proposed CGA-based method, the mutation process is not the same as the traditional mutation method of exchanging the ' 0,1 ' sequence, but by a chaotic re-initialization. That is, when an individual is chosen to do the mutation, it is reinitialized by the chaotic initialization method, that is proposed in Section 4.2. Similar to crossover, a pre-defined number of genes will be selected by the Chaotic Selection method according to the specified probability, or the so-called 'mutation rate' (MR), in mutation operation. And this increases the diversity of the allocation of a ship to berth and the scheduling order.

\subsection{EXPERIMENTAL SIMULATIONS}

To demonstrate the difference in performance of the existing formulation in literature and the proposed one, computational analyses of the proposed PBAP using the proposed CGA-based method were conducted. Cases used in the experiments were generated randomly but systematically primarily [22]. Statistics from other literature and real-world instance had also been used to provide reasonable and realistic data input for the numerical experiments $[33,50]$.

The basic problem in which 25 calling ships with various ship lengths and container handling volumes are handled at a multi-user terminal (MUT) with 5 berths of different berth lengths was developed [22]. 10 data sets of container handling volume were prepared for the calling ship set. The containers handling volume followed a uniform 
distribution, ranged between 50 Twenty-foot equivalent units (TEUs) and 1,000 TEUs [22], with a total handling volume of 11,092 TEUs [51]. The ships had different arrival time and were set to have an inter-arrival time between 0 hour and 5 hours based on the distribution of ship arrival at Port of Colombo [33]. The handling time at any of the five berths was calculated by multiplying the average handling time per one container observed in the Port of Kobe (i.e., 2 minutes) and the handling volume [22]. The details of other parameters such as berth length [51], ship length [50], ship's container handling volume and ship's arrival time [33] are shown in Tables 6, 7 and 8, respectively. After all, 10 cases were calculated for the computational analyses. The planning horizon (Pj) served the 25 calling ships is six days as for fair comparison with the one in literature [22]. The ship differentiating weight (wi) was set to 1 for all calling ships to obtain the minimal total service time for PBAP as concluded by Imai et al. [22] as well as to have clear while simplified discussion.

The CGA-based method was then applied to solve the 10 cases independently for 10 times. The solution procedure was coded in MatLab and was run on a PC with Intel Core i7-4790K CPU at 4GHz with 8GB RAM. The computational time is about 1 second.

Table 6: Parameters of the numerical example

\begin{tabular}{lll}
\hline Berth ID & Berth length $\left(\boldsymbol{R}_{\boldsymbol{j}}\right)$ [51] & $\begin{array}{l}\text { Ships allowed to berth } \\
\text { (due to physical constraints) }\end{array}$ \\
\hline 1 and 2 & $300 \mathrm{~m}$ & Ship 1 to Ship 20 \\
3 and 4 & $320 \mathrm{~m}$ & Ship 1 to Ship 20 \\
5 & $350 \mathrm{~m}$ & Ship 1 to Ship 25 \\
\hline & & \\
\cline { 2 - 2 } & Calling ship ID & Ship length $\left(\boldsymbol{L}_{\boldsymbol{i}}\right)[\mathbf{5 0}]$ \\
\hline & $\mathrm{V}_{1}$ to $\mathrm{V}_{10}$ & $300 \mathrm{~m}$ \\
& $\mathrm{~V}_{11}$ to $\mathrm{V}_{20}$ & $300 \mathrm{~m}$ \\
& $\mathrm{~V}_{21}$ to $\mathrm{V}_{25}$ & $320 \mathrm{~m}$ \\
\hline
\end{tabular}

Table 7: Ship's container handling volume (TEUs) $[22,51]$

\begin{tabular}{lllllllllll}
\hline Calling & Set 1 & Set 2 & Set 3 & Set 4 & Set 5 & Set 6 & Set 7 & Set 8 & Set 9 & Set 10 \\
Ship ID & & & & & & & & & & \\
\hline $\mathrm{V}_{1}$ & 51 & 51 & 989 & 585 & 58 & 58 & 163 & 51 & 585 & 506 \\
$\mathrm{~V}_{2}$ & 585 & 54 & 901 & 51 & 54 & 163 & 58 & 234 & 818 & 383 \\
$\mathrm{~V}_{3}$ & 234 & 58 & 866 & 818 & 163 & 54 & 589 & 606 & 506 & 901 \\
$\mathrm{~V}_{4}$ & 818 & 64 & 832 & 234 & 473 & 989 & 54 & 383 & 901 & 832 \\
$\mathrm{~V}_{5}$ & 606 & 137 & 818 & 506 & 989 & 473 & 473 & 832 & 759 & 759 \\
$\mathrm{~V}_{6}$ & 506 & 163 & 759 & 606 & 208 & 190 & 190 & 215 & 866 & 51 \\
$\mathrm{~V}_{7}$ & 383 & 190 & 725 & 901 & 190 & 208 & 208 & 725 & 538 & 585 \\
$\mathrm{~V}_{8}$ & 901 & 208 & 606 & 383 & 396 & 137 & 137 & 339 & 64 & 234 \\
$\mathrm{~V}_{9}$ & 832 & 215 & 585 & 759 & 137 & 396 & 396 & 137 & 396 & 818 \\
$\mathrm{~V}_{10}$ & 759 & 234 & 538 & 832 & 64 & 339 & 339 & 190 & 208 & 606 \\
$\mathrm{~V}_{11}$ & 215 & 339 & 506 & 866 & 339 & 64 & 64 & 989 & 473 & 64 \\
$\mathrm{~V}_{12}$ & 866 & 383 & 473 & 215 & 538 & 725 & 725 & 163 & 54 & 137 \\
$\mathrm{~V}_{13}$ & 725 & 396 & 396 & 538 & 725 & 538 & 538 & 58 & 51 & 396 \\
$\mathrm{~V}_{14}$ & 538 & 473 & 383 & 725 & 866 & 215 & 215 & 585 & 234 & 190 \\
$\mathrm{~V}_{15}$ & 339 & 506 & 339 & 64 & 215 & 866 & 866 & 818 & 606 & 208 \\
$\mathrm{~V}_{16}$ & 64 & 538 & 234 & 339 & 759 & 832 & 832 & 506 & 383 & 215 \\
$\mathrm{~V}_{17}$ & 137 & 585 & 215 & 396 & 832 & 759 & 759 & 901 & 832 & 866 \\
$\mathrm{~V}_{18}$ & 396 & 606 & 208 & 137 & 901 & 383 & 383 & 759 & 215 & 725 \\
$\mathrm{~V}_{19}$ & 190 & 725 & 190 & 208 & 383 & 901 & 901 & 866 & 725 & 538 \\
$\mathrm{~V}_{20}$ & 208 & 759 & 163 & 190 & 506 & 606 & 606 & 538 & 339 & 339 \\
$\mathrm{~V}_{21}$ & 989 & 818 & 137 & 473 & 606 & 506 & 506 & 64 & 137 & 989 \\
$\mathrm{~V}_{22}$ & 473 & 832 & 64 & 989 & 818 & 234 & 234 & 396 & 190 & 473 \\
$\mathrm{~V}_{23}$ & 163 & 866 & 58 & 54 & 234 & 818 & 818 & 208 & 989 & 163 \\
$\mathrm{~V}_{24}$ & 54 & 901 & 54 & 163 & 585 & 51 & 51 & 473 & 163 & 54 \\
$\mathrm{~V}_{25}$ & 58 & 989 & 51 & 58 & 51 & 585 & 585 & 54 & 58 & 58 \\
\hline & & & & & & & & & &
\end{tabular}


Table 8: Ship's arrival time

\begin{tabular}{llll}
\hline Calling Ship ID & Inter-arrival time (hour) [33] & Arrival time $\boldsymbol{A}_{\boldsymbol{i}}$ (hour) & Arrival time $\boldsymbol{A} \boldsymbol{i}$ (minute) \\
\hline $\mathrm{V}_{1}$ & - & 3.45 & 207 \\
$\mathrm{~V}_{2}$ & 0.5 & 3.95 & 237 \\
$\mathrm{~V}_{3}$ & 1 & 4.95 & 297 \\
$\mathrm{~V}_{4}$ & 3.5 & 8.45 & 507 \\
$\mathrm{~V}_{5}$ & 2.3 & 10.75 & 645 \\
$\mathrm{~V}_{6}$ & 2.6 & 13.35 & 801 \\
$\mathrm{~V}_{7}$ & 0.9 & 14.25 & 855 \\
$\mathrm{~V}_{8}$ & 0.2 & 14.45 & 867 \\
$\mathrm{~V}_{9}$ & 1.7 & 16.15 & 969 \\
$\mathrm{~V}_{10}$ & 0.3 & 16.45 & 987 \\
$\mathrm{~V}_{11}$ & 3 & 19.45 & 1,167 \\
$\mathrm{~V}_{12}$ & 2.5 & 21.95 & 1,317 \\
$\mathrm{~V}_{13}$ & 1.2 & 23.15 & 1,389 \\
$\mathrm{~V}_{14}$ & 0.8 & 23.95 & 1,437 \\
$\mathrm{~V}_{15}$ & 3.8 & 27.75 & 1,665 \\
$\mathrm{~V}_{16}$ & 2.1 & 29.85 & 1,791 \\
$\mathrm{~V}_{17}$ & 0.1 & 29.95 & 1,797 \\
$\mathrm{~V}_{18}$ & 3.12 & 33.07 & $1,984.2$ \\
$\mathrm{~V}_{19}$ & 4.6 & 37.67 & $2,260.2$ \\
$\mathrm{~V}_{20}$ & 1.25 & 38.92 & $2,335.2$ \\
$\mathrm{~V}_{21}$ & 2.85 & 41.77 & $2,506.2$ \\
$\mathrm{~V}_{22}$ & 3.75 & 45.52 & $2,731.2$ \\
$\mathrm{~V}_{23}$ & 0.45 & 45.97 & $2,758.2$ \\
$\mathrm{~V}_{24}$ & 0.65 & 46.62 & $2,797.2$ \\
$\mathrm{~V}_{25}$ & 1.8 & 48.42 & $2,905.2$ \\
\hline
\end{tabular}

\subsection{Parameters Setting of CGA-based Method}

The population size is set as 30 as suggested by the literature [22] and for a fair comparison. Reviewing the fitness values of solution changing with the generation, no noteworthy improvement in solution quality is observed after 950 generations using SGA-based method while no noteworthy improvement in solution quality is observed after 650 generations using our proposed CGA-based method. A conservative value of 1,000 is hence chosen for the number of generations needed for convergence, and thereby as the termination condition.

Regarding the crossover and mutation rates, since there is no strict guideline in literature regarding the values to be assigned, and it is reported that different combinations of values work better for different problems [52, 53], for the proposed formulation, different combinations of the crossover and mutation rates were applied to solve the 10 cases independently for 10 times to demonstrate the influence of different rates on the performance of genetic search in CGA-based method. The range of the crossover rate is from 0.1 to 1.0 with 0.1 increases and the mutation rate from 0.1 to 1.0 with 0.1 increases. 100 combinations in total were tested. The minimum, average, and maximum total service time and fitness values obtained for the 10 cases with different crossover and mutation rates were recorded. The results show that the total service time and hence the fitness values obtained fluctuated vigorously in different combinations. When solving the 10 cases, optimal solutions were obtained when crossover and mutation rates were 0.7 and 0.4 , respectively. In point of experimental results, it can be concluded that the best results were obtained at the crossover rate of 0.7 and mutation rate of 0.4. Although the crossover rate and mutation rate obtained seems quite large and may result in a high level of chromosome disruption which lowers the solution quality, the results can, in fact, be supported by the previous researches. The previous papers also concluded that "a high level of string disruption is desirable in small populations" [53,54]. The results obtained from sensitivity analysis should, therefore, be regarded as reasonable and suitable.

\subsection{Simulation Results}

The termination criteria, crossover rate and mutation rate were applied to solve the Case 1 independently for 10 times and subsequently to solve the 10 cases independently so as to examine and compare how the two formulations 
differ in performance in terms of the number of ships assigned to each berth and the number of successfully berthed ships. Besides, the SGA-based method [22] and the CGA-based method were applied to solve the 10 cases so as to illustrate the effectiveness of our newly proposed CGA-based method.

\subsubsection{Number of Ships Assigned to Each Berth}

The numbers of ships assigned to each berth under the two formulations were plotted in Fig. 9 to Fig. 12 . Fig. 9 and Fig. 10 show the results that ships are more or less evenly distributed under the formulation proposed by Imai et al. [22] while ships are more congested for a particular berth (i.e., Berth 5 in this problem) under our proposed formulation (Fig. 11 and Fig. 12).

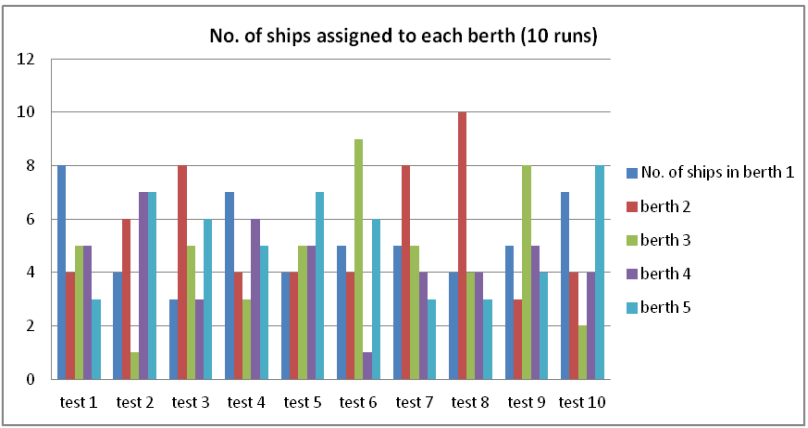

Fig. 9: Number of ships assigned to each berth under formulation proposed by Imai et al. [22] (10 runs)

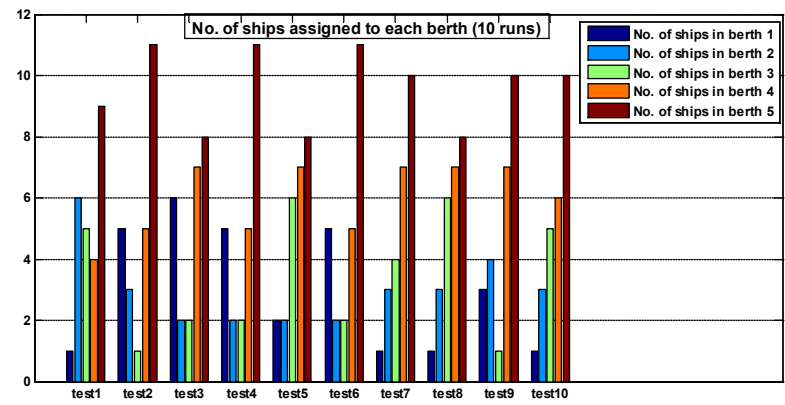

Fig. 11: Number of ships assigned to each berth under our proposed formulation (10 runs)

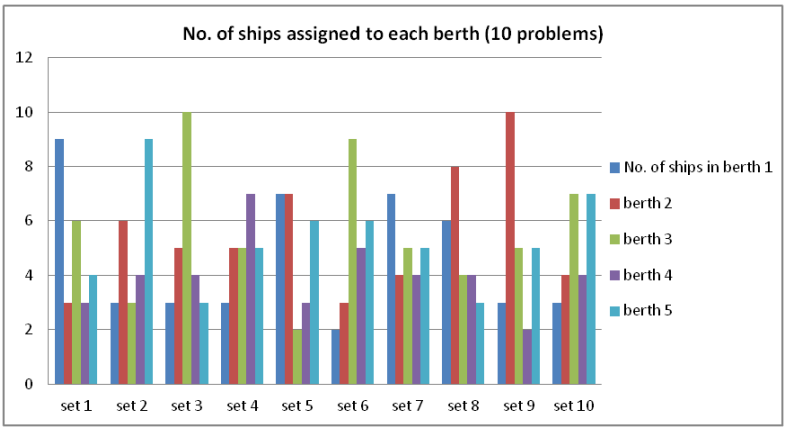

Fig. 10: Number of ships assigned to each berth under formulation proposed by Imai et al. [22] (10 cases)

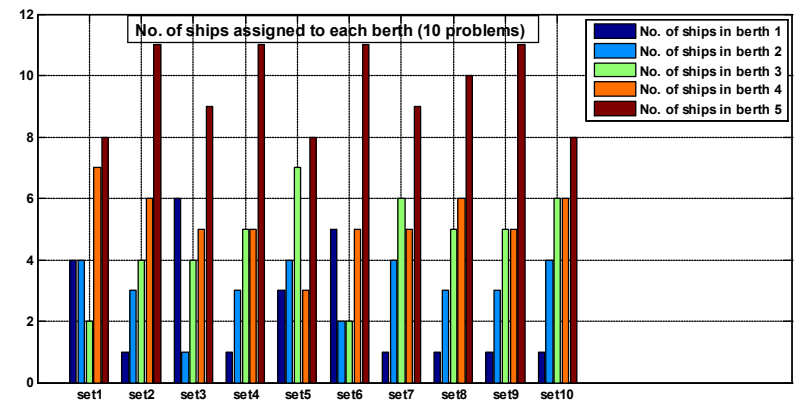

Fig. 12: Number of ships assigned to each berth under our proposed formulation (10 cases)

The major difference between the two formulations is the presence of physical constraints. The existing formulation assumes "each berth can service one ship at a time regardless of the ship's size and there are no physical restrictions" [22], while in practice there are no berths with an infinitely large size which can physically accommodate any ship assigned to it. Therefore, physical constraints must be taken into account when dealing with berth allocation as well as when considering total service time minimization in PBAP. Due to the consideration of physical condition (actually berth length being considered) of berths in our proposed formulation, ships cannot be handled by any of the available berth despite the berth length. Instead, ships can only be serviced at suitable berth(s) with sufficiently long berth length. As berth 5 is the only berth which can physically accommodate any of the ship assigned to it, those ships which cannot be served at the originally-assigned berth will then be assigned to berth 5 . As a result, much more ships are assigned to berth 5 than that to others.

From the experimental results, it can be concluded that ships are assigned to berth considering only the total service time under the formulation in literature. On the other hand, our proposed formulation has taken physical constraints into account when assigning and scheduling ships to berths. Subsequently, the ships are assigned only to berth which can physically accommodate them. Therefore, ships are more or less evenly distributed under the formulation proposed by Imai et al. [22] while ships are more congested at particular berth (i.e., Berth 5) due to physical constraints under our proposed formulation. Also, it can be concluded that physical constraints have to be considered prior to minimizing the total service time and optimizing the PBAP. 


\subsubsection{Total Service Time}

To illustrate the effectiveness of our newly proposed CGA-based method, the SGA-based method [22] was also applied to solve the 10 PBAP cases. The comparison results obtained regarding the total service time for the 10 cases are shown in Fig. 13 to Fig. 22, respectively. The results show that the proposed CGA-based method converges faster to the optima in most cases and can achieve shorter total service time than the SGA-based method in all the 10 cases, which fully illustrate the effectiveness of our newly proposed CGA-based method. Also, the average total service time out of 30 runs for the 10 cases are obtained and reported in Table 9 and Fig. 23, which also reveal the strong power of our newly proposed CGA-based method in dealing with PBAP.

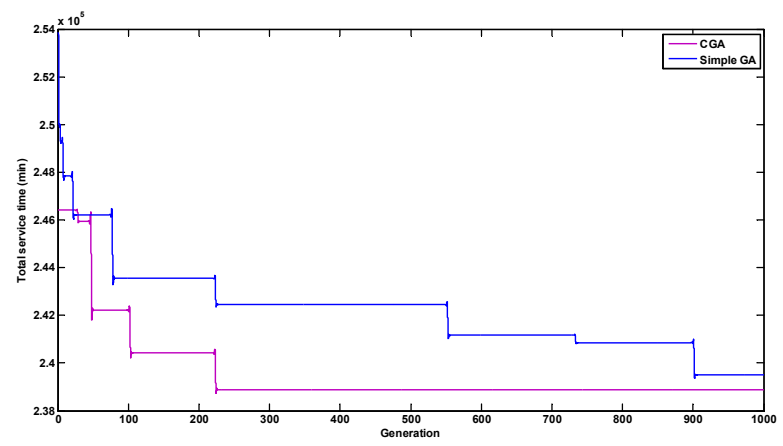

Fig. 13: Comparison between CGA and SGA-based methods for Case 1

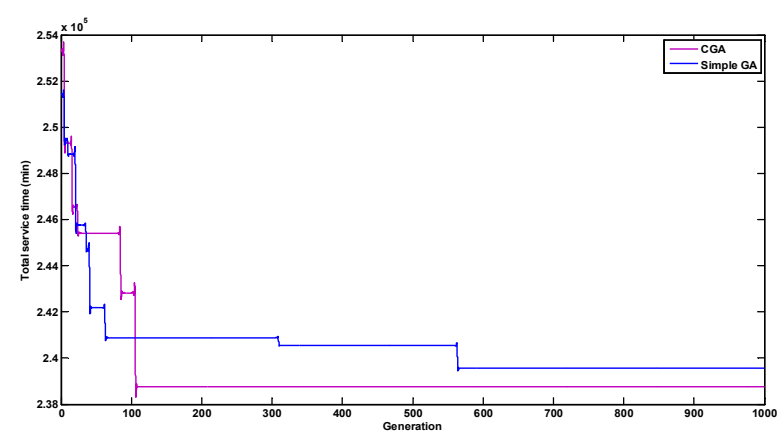

Fig. 15: Comparison between CGA and SGA-based methods for Case 3

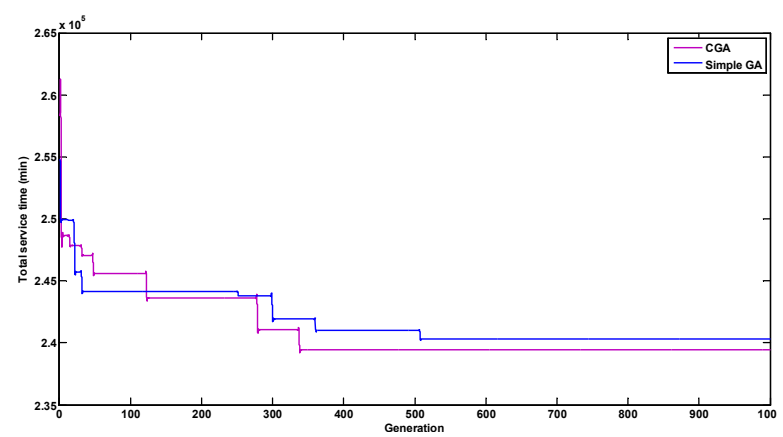

Fig. 17: Comparison between CGA and SGA-based methods for Case 5

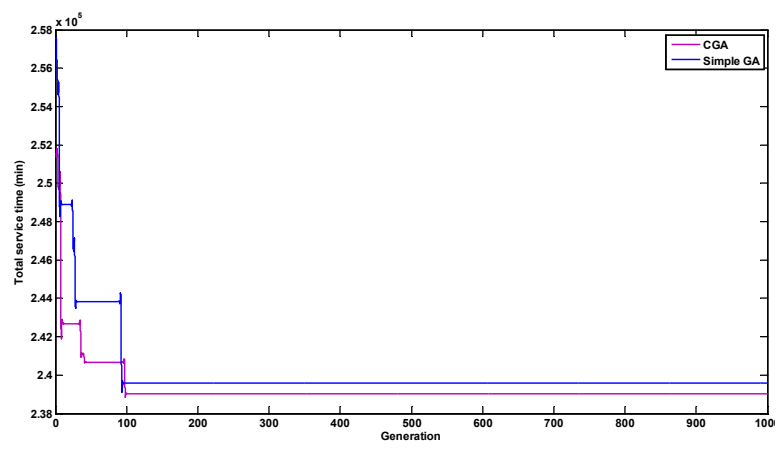

Fig. 14: Comparison between CGA and SGA-based methods for Case 2

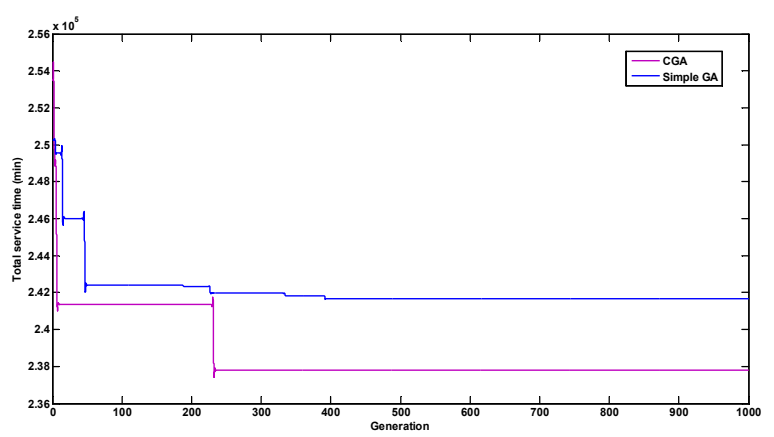

Fig. 16: Comparison between CGA and SGA-based methods for Case 4

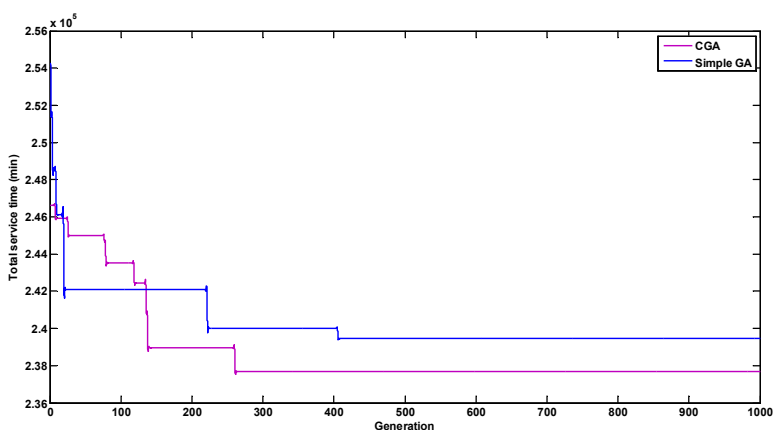

Fig. 18: Comparison between CGA and SGA-based methods for Case 6 


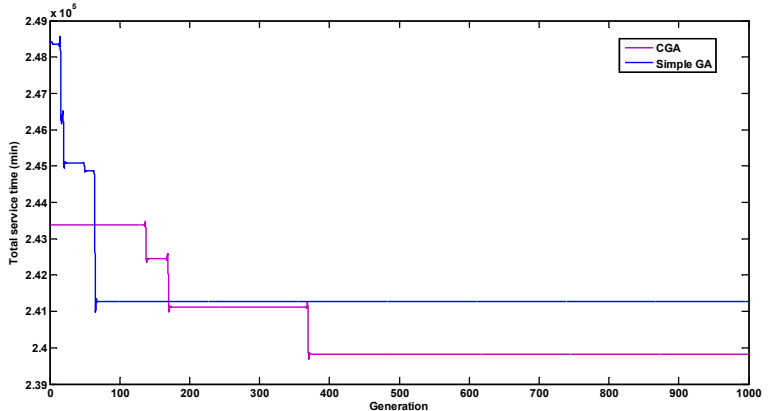

Fig. 19: Comparison between CGA and SGA-based methods for Case 7

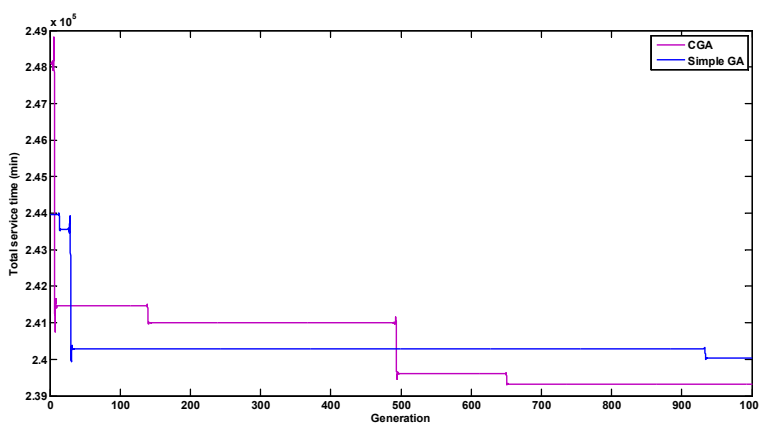

Fig. 21: Comparison between CGA and SGA-based methods for Case 9

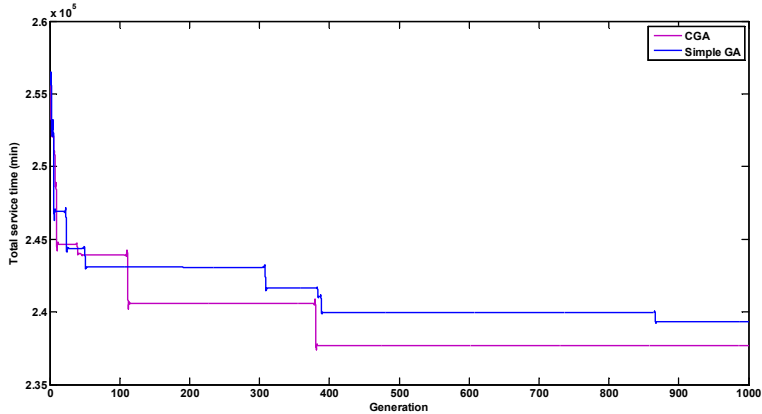

Fig. 20: Comparison between CGA and SGA-based methods for Case 8

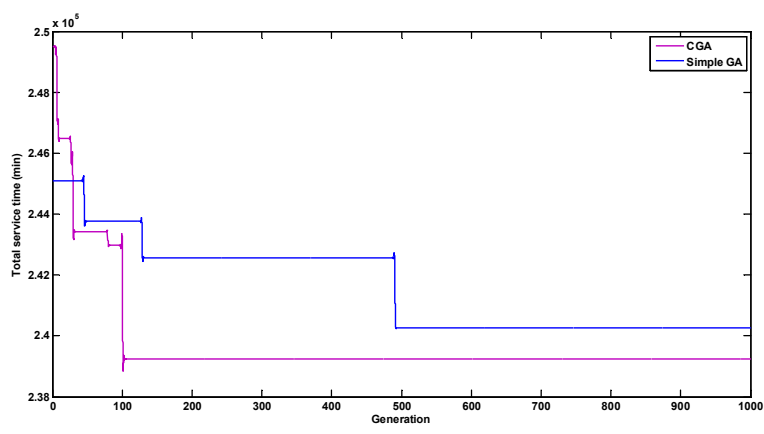

Fig. 22: Comparison between CGA and SGA-based methods for Case 10

Table 9: Comparison of average total service time between CGA and SGA-based methods for 10 cases

\begin{tabular}{l||ccccc}
\hline \multirow{2}{*}{\begin{tabular}{l} 
Method \\
\cline { 2 - 6 }
\end{tabular}} & $\mathbf{1}$ & $\mathbf{2}$ & $\mathbf{3}$ & $\mathbf{4}$ & $\mathbf{5}$ \\
\hline \multirow{2}{*}{ CGA-based (min) } & $2.3812 \mathrm{E} 05$ & $2.3700 \mathrm{E} 05$ & $2.3566 \mathrm{E} 05$ & $2.3606 \mathrm{E} 05$ & $2.3632 \mathrm{E} 05$ \\
\hline \multirow{2}{*}{ SGA-based (min) } & $2.4116 \mathrm{E} 05$ & $2.3880 \mathrm{E} 05$ & $2.3642 \mathrm{E} 05$ & $2.3917 \mathrm{E} 05$ & $2.3906 \mathrm{E} 05$ \\
\hline \hline \multirow{2}{*}{ Method } & \multicolumn{5}{c}{ Case } \\
\cline { 2 - 6 } & $\mathbf{6}$ & $\mathbf{7}$ & $\mathbf{8}$ & $\mathbf{9}$ \\
\hline CGA-based (min) & $2.3793 \mathrm{E} 05$ & $2.3872 \mathrm{E} 05$ & $2.3840 \mathrm{E} 05$ & $2.3688 \mathrm{E} 05$ & $2.3818 \mathrm{E} 05$ \\
\hline SGA-based (min) & $2.3999 \mathrm{E} 05$ & $2.4045 \mathrm{E} 05$ & $2.4085 \mathrm{E} 05$ & $2.3988 \mathrm{E} 05$ & $2.3917 \mathrm{E} 05$ \\
\hline
\end{tabular}

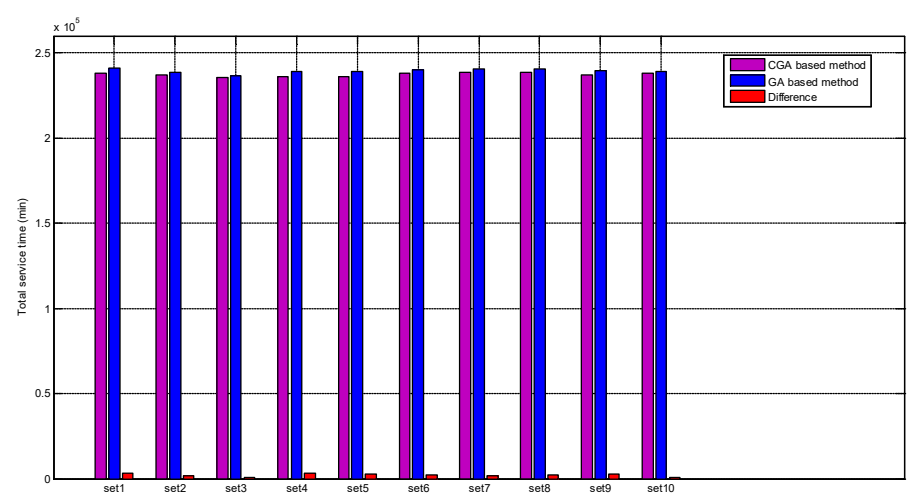

Fig. 23: Comparison of average total service time between CGA and SGA-based methods for 10 cases 


\subsubsection{Number of Successfully Berthed Ships}

In this research, one of the objectives is to maximize terminal serviceability; therefore, it is of our interest to study how the two formulations perform regarding the number of successfully berthed ships. Although the costs of handling one calling ship are not considered in this research, it is reasonable to believe that the more calling ships a terminal can service, the more cargos it can handle and the more cargo handling charges and profits it can enjoy. Also, it is reported that terminal operators always want to minimize the costs resulted from long total service time, such as the penalty costs resulting from delayed departures of ships $[55,56]$, the costs resulted from a late start of ship handling [34], the costs of low resources utilization [55], and the additional handling costs resulted from berth shift [34]. Therefore, a feasible formulation and an optimization method for berth allocation, which minimizes total service time while maximizes the number of successfully berthed ships, are suggested to be able to maximize terminal serviceability.

When a ship is assigned to a berth which cannot physically accommodate it due to the physical relationship between berth length and ship length, it will be regarded as an unsuccessfully berthed ship; otherwise, it will be regarded as a successfully berthed ship. The results regarding the number of successfully berthed ships under the two formulations are shown in Fig. 24 and Fig. 25. The results show that all the ships are successfully berthed when adopting the CGA-based method in solving the proposed formulation; however, some of the ships are assigned to unsuitable berths and thus unsuccessfully berthed using the formulation in the literature [22].

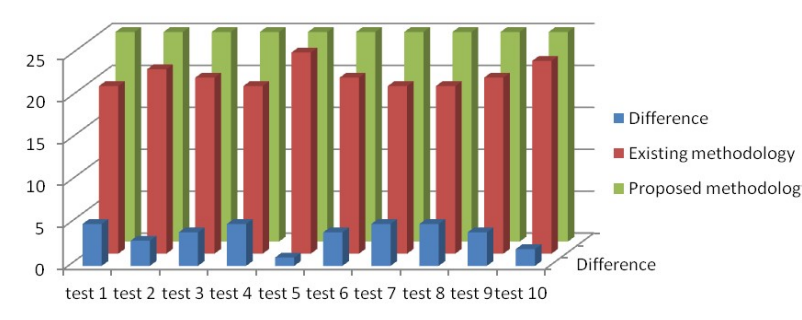

Fig. 24: Comparison of the number of successfully berthed ships (10 runs)

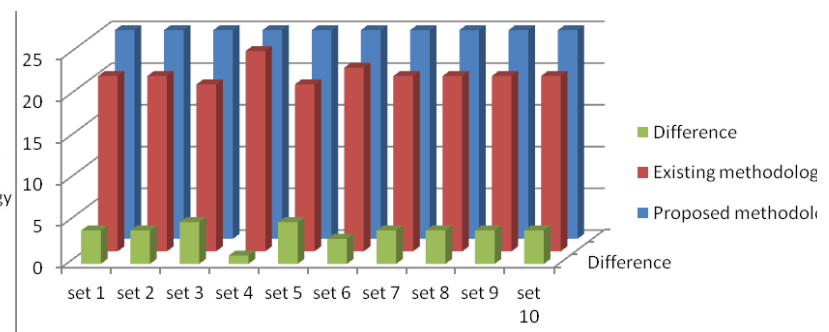

Fig. 25: Comparison of the number of successfully berthed ships (10 cases)

Ideally, all the calling ships can be successfully berthed. However, this is only possible if every berth has a sufficiently large size capable of serving any of the ships assigned to it regardless of their size. Such a terminal layout, however, turns out to be very costly as there is a considerable redundant fleet when the calling ships are small in size. Indeed, such a layout is rather unrealistic as the size of container ships varies with time, and it would be unpractical and impossible for terminal operators to expand the length of the berths whenever they desire.

When the existing formulation is applied to solve PBAP, it is assumed that all the calling ships can be served [22]; however, it is just based on their neglect of physical condition of berths and thus the physical relationships between berth lengths and ship lengths. Their formulation is, in fact, an infeasible one which cannot assign and schedule all the calling ships in line with what they presumed. On the other hand, all the calling ships can be successfully berthed utilizing the proposed formulation as expected and effectively allocated utilizing the proposed CGA-based method. Therefore, it is believed that physical constraints considerably impact the number of successfully berthed ships in PBAP as well as terminal serviceability. An optimization approach for PBAP must take physical constraints into account in order to make it feasible. The proposed formulation, which has taken the physical condition of a berth and thus the physical relationships between berth lengths and ship lengths into account, is therefore suggested to be capable of optimally assigning and scheduling calling ships to berths with the objective of minimizing total service time and make it outperformed the existing one.

\subsection{CONCLUSION}

There are always difficulties posed on berth allocation, such as the diversity of ship sizes and cargo handling volumes, and dilemma encountered by terminal operators in balancing service priorities and maximizing terminal productivity during berth allocation. This research contributed to deal with the dilemma terminal operators encountered in balancing service priorities and terminal productivity maximization during berth allocation. Although there are existing formulations for PBAP in literature, the majority of them considered only the hard priority explicitly assigned to the calling ships and caused dissatisfaction to ship companies and failed to balance service order with terminal productivity. To our knowledge, only three existing studies have considered a soft 
priority; however, they considered no physical constraints and lowered their applicability. Addressing the insufficient researches taking soft priority into account during berth allocation and the limitation of the existing formulations of PBAP, a feasible and more applicable formulation of PBAP using CGA-based method is proposed in this research. The proposed formulation of PBAP with physical constraints is then modeled, applied to solve 10 cases and compared with the existing formulation and SGA-based method. Utilizing the proposed formulation and CGA-based method, terminal operators can have a better balance between service priorities and maximizing terminal productivity during berth allocation in an efficient and convenient way. In addition, experimental results show that more calling ships can be served by the terminal with the proposed formulation and CGA-based method. Accordingly, the terminal revenue and serviceability can be enhanced. Therefore, it is believed that the proposed formulation of PBAP and CGA-based method outperformed the existing one in literature. The problem size is a major limitation of this research. To enhance the reliability of the proposed PBAP with physical constraints and the adoption of CGA-based method in solving the problem, it is recommended to enlarge the problem sizes and study the limitation of problem sizes in a future study. Also, it is suggested to consider more physical as well as technical constraints, such as availability of cranes, in future research to facilitate the applicability and feasibility of the proposed formulation and adopted the method, so as to provide a more holistic approach in dealing with PBAP.

\section{ACKNOWLEDGEMENT}

The authors thank the editors and reviewers for their valuable comments and suggestions that have improved the paper's quality. The authors would also like to thank the Department of Industrial and Systems Engineering (ISE), The Hong Kong Polytechnic University (PolyU) for their financial assistance to the involved research student (RTPG). This work is supported in part by a grant from the Research Grants Council of the Hong Kong Special Administrative Region, China (PolyU 152108/15E), and a grant from National Natural Science Foundation (NNSF) of China (61773282). Our gratitude is also extended to the E-Logistics Group, PRISC of The Hang Seng University of Hong Kong, and the School of Electrical Engineering and Information Engineering of Tianjin University, for their support in this work.

\section{REFERENCES}

[1] L. Zhen, L. H. Lee, \& E. P. Chew, "A decision model for berth allocation under uncertainty". European Journal of Operational Research, Vol. 212, No. 1, 2011, pp. 54-68.

[2] J. Tongzon, \& Heng, W., "Port privatization, efficiency and competitiveness: some empirical evidence from container ports (terminals)". Transportation Research Part A, Vol. 39, No. 5, 2005, pp. 405-424.

[3] R. Stahlbock, \& S. Voß, "Operations research at container terminals: a literature update”. OR Spectrum, Vol. 30, No. 1, 2008, pp. 1-52.

[4] P. Hansen, C. Oguz, \& N. Mladenovic, "Variable neighborhood search for minimum cost berth allocation". European Journal of Operational Research, Vol. 191, No. 3, 2008, pp. 636-649.

[5] A. Imai, E. Nishimura, M. Hattori, \& S. Papadimitriou, "Berth allocation at indented berths for megacontainerships". European Journal of Operational Research, Vol. 179, No. 2, 2007, pp. 579-593.

[6] A. Imai, J.T. Zhang, E. Nishimura, \& S. Papadimitriou, "The berth allocation problem with service time and delay time objectives". Maritime Economics and Logistics, Vol. 9, No. 4, 2007, pp. 269-290.

[7] L. Henesey, "A multi agent based simulator for managing a container terminal", in The 2nd European Workshop on Multi-Agent Systems (EUMAS 2004), Barcelona, Spain, 16-17 December 2004.

[8] D. Steenken, S. Voß, \& R. Stahlbock, "Container terminal operation and operations research-a classification and literature review". OR Spectrum, Vol. 26, No. 1, 2004, pp. 3-49.

[9] K. H. Kim, "Models and methods for operations in port container terminals". In: Langevin A, Riopel D (eds) Logistics Systems: Sesign and Optimization. Springer, Berlin Heidelberg New York, 2005, pp. 213-243. 
[10] K.G. Murty, J. Liu, Y. W. Wan, \& R. Linn, "A decision support system for operations in a container terminal”. Decision Support Systems, Vol. 39, No. 3, 2005, pp. 309-332.

[11] W. C. Ng, \& K. L. Mak, "Quay crane scheduling in container terminals". Engineering Optimization, Vol. 38, No. 6, 2006, pp. 723-737.

[12] H. O. Günther, \& K. H. Kim, "Container terminals and terminal operations". OR Spectrum, Vol. 28, No. 4, 2006, pp. 437-445.

[13] W. Zhou, \& X. Wu, "An efficient optimal solution of a two-crane scheduling problem". Asia-Pacific Journal of Operational Research, Vol. 26, No. 1, 2009, pp. 31-58.

[14] C. Zhang, Z. Zhang, L. Zheng, \& L. Miao, "A decision support system for the allocation of yard cranes and blocks in container terminals". Asia-Pacific Journal of Operational Research, Vol. 28, No. 6, 2011, pp. 803829.

[15] I. F. A. Vis, \& R. de Koster, "Transshipment of containers at a container terminal: an overview". European Journal of Operational Research, Vol. 147, No. 1, 2003, pp. 1-16.

[16] E. Nishimura, A. Imai, \& S. Papadimitriou, "Berth allocation planning in the public berth system by genetic algorithms". European Journal of Operational Research, Vol. 131, No. 2, 2001, pp. 282-292.

[17] P. Hansen, \& C. Oguz, "A note on formulations of the static and dynamic berth allocation problems". Les Cahiers du GERAD, Vol. 30, 2003, pp. 1-17.

[18] A. Imai, E. Nishimura, \& S. Papadimitriou, "The dynamic berth allocation problem for a container port". Transportation Research Part B: Methodological, Vol. 35, No. 4, 2001, pp. 401-417.

[19] C. Y. Cheong, K. C. Tan, D. K. Liu, \& C. J. Lin, "Multi-objective and prioritized berth allocation in container ports". Annals of Operations Research, Vol. 180, No. 1, 2010, pp. 63-103.

[20] S. R. Seyedalizadeh Ganji, A. Babazadeh, \& N. Arabshahi, "Analysis of the continuous berth allocation problem in container ports using a genetic algorithm", Journal of Marine Science and Technology, Vol. 15, No. 4, 2010, pp. 408-416.

[21] K. Buhrkal, S. Zuglian, S. Ropke, J. Larsen, \& R. Lusby, "Models for the discrete berth allocation problem: A computational comparison". Transportation Research Part E: Logistics and Transportation Review, Vol. 47, No. 4, 2011, pp. 461-473.

[22] A. Imai, E. Nishimura, \& S. Papadimitriou, "Berth allocation with service priority". Transportation Research Part B: Methodological, Vol. 37, No. 5, 2003, pp. 437-457.

[23] J. F. Cordeau, G. Laporte, P. Legato, \& L. Moccia, "Models and tabu search heuristics for the berthallocation problem". Transportation Science, Vol. 39, No. 4, 2005, pp. 526-538.

[24] E. Lalla-Ruiz, C. Expósito-Izquierdo, B. Melián-Batista, \& J. M. Moreno-Vega, “A set-partitioning-based model for the berth allocation problem under time-dependent limitations". European Journal of Operational Research, Vol. 250, No. 3, 2016, pp. 1001-1012.

[25] L. Zhen, "Tactical berth allocation under uncertainty". European Journal of Operational Research, Vol. 247, No. 3, 2015, pp. 928-944.

[26] D. Xu, C. L. Li, \& J. Y. T. Leung, "Berth allocation with time-dependent physical limitations on vessels". European Journal of Operational Research, Vol. 216, No. 1, 2012, pp. 47-56.

[27] S. W. Lin, K. C. Ying, \& S. Y. Wan, "Minimizing the total service time of discrete dynamic berth allocation problem by an iterated greedy heuristic". The Scientific World Journal, Vol. 2014, 2014, pp. 1-12. 
[28] K. K. Lai, \& K. Shih, "A study of container berth allocation". Journal of Advanced Transportation, Vol. 26, No. 1, 1992, pp. 45-60.

[29] A. Imai, K. Nagaiwa, \& W. T. Chan, "Efficient planning of berth allocation for container terminals in Asia". Journal of Advanced Transportation, Vol. 31, No. 1, 1997, pp. 75-94.

[30] C. Y. Cheong, K. C. Tan, \& D. K. Liu, "Solving the berth allocation problem with service priority via multiobjective optimization", in 2009 IEEE Symposium on Computational Intelligence in Scheduling, Nashville, USA, 30 March - 2 April 2009.

[31] C. Y. Cheong, K. C. Tan, D. K. Liu, \& C. J. Lin, "Multi-objective and prioritized berth allocation in container ports". Annals of Operations Research, Vol. 180, No. 1, 2010, pp. 63-103.

[32] E. Ursavas, "Priority control of berth allocation problem in container terminals". Annals of Operations Research, 2015, pp. 1-20.

[33] A. Imai, E. Nishimura, \& S. Papadimitriou, "Berthing ships at a multi-user container terminal with a limited quay capacity". Transportation Research Part E, Vol. 44, No. 1, 2008, pp. 136-151.

[34] Y. M. Park, \& K. H. Kim, "A scheduling method for berth and quay cranes". OR Spectrum, Vol. 25, No. 1, 2003, pp. 1-23.

[35] J. Karafa, M. M. Golias, S. Ivey, G. K. D. Saharidis, \& N. Leonardos, "The berth allocation problem with stochastic vessel handling times". The International Journal of Advanced Manufacturing Technology, Vol. 65, No. 1, 2013, pp. 473-484.

[36] C. Y. Cheong, \& K. C. Tan, "A multi-objective multi-colony ant algorithm for solving the berth allocation problem". Advances of Computational Intelligence in Industrial Systems, Vol. 116, 2008, pp. 333-350.

[37] M. M. Golias, "A bi-objective berth allocation formulation to account for vessel handling time uncertainty". Maritime Economics \& Logistics, Vol. 13, No. 4, 2011, pp. 419-441.

[38] E. Lalla-Ruiz, B. Melian-Batista, \& J. M. Moreno-Vega, "Artificial intelligence hybrid heuristic based on tabu search for the dynamic berth allocation problem". Engineering Applications of Artificial Intelligence, Vol. 25, No. 6, 2012, pp. 1132-1141.

[39] A. H. Tsai, C. N. Lee, J. S. Wu, \& F. S. Chang, "Novel wharf-based genetic algorithm for berth allocation planning". Soft Computing, 2016. doi:10.1007/s00500-016-2272-1.

[40] H. Y. K. Lau, \& Y. Zhao, "Integrated scheduling of handling equipment at automated container terminals". International Journal of Production Economics, Vol. 112, No. 2, 2008, pp. 665-682.

[41] S. Theofanis M. Boile, \& M. Golias, "An optimization based genetic algorithm heuristic for the berth allocation problem", in Proceedings of IEEE Congress on Evolutionary Computation (CEC 2007), 2008, pp. 4439-4445.

[42] X. Yuan, Y. Yuan, \& Y. Zhang, "A hybrid chaotic genetic algorithm for short-term hydro system scheduling". Mathematics and Computers in Simulation, Vol. 59, No. 4, 2002, pp. 319-327.

[43] W. C. Hong, Y. Dong, L. Y. Chen, \& S. Y. Wei, "SVR with hybrid chaotic genetic algorithms for tourism demand forecasting". Applied Soft Computing, Vol. 11, No. 2, 2011, pp. 1881-1890.

[44] W. C. Hong, Y. Dong, W. Y. Zhang, L. Y. Chen, \& B. K. Panigrahi, "Cyclic electric load forecasting by seasonal SVR with chaotic genetic algorithm". International Journal of Electrical Power \& Energy Systems, Vol. 44, No. 1, 2013, pp. 604-614. 
[45] A. Imai, E. Nishimura, \& S. Papadimitriou, Corrigendum to "The dynamic berth allocation problem for a container port" [Transportation Research Part B 35 (2001) 401-417], Transportation Research Part B: Methodological, Vol. 39, No. 3, 2005, pp. 197-197.

[46] P. Zhou, \& H. Kang, "Study on berth and quay-crane allocation under stochastic environments in container terminal". Systems Engineering Theory \& Practice, Vol. 28, No. 1, 2008, pp. 161-169.

[47] C. Liang, Y. Huang, \& Y. Yang, "A quay crane dynamic scheduling problem by hybrid evolutionary algorithm for berth allocation planning". Computers \& Industrial Engineering, Vol. 56, No. 3, 2009, pp. 1021-1028.

[48] G. Saharidis, M. Golias, M. Boile, S. Theofanis, \& M. Ierapetritou, "The berth scheduling problem with customer differentiation: a new methodological approach based on hierarchical optimization". The International Journal of Advanced Manufacturing Technology, Vol. 46, No. 1, 2010, pp. 377-393.

[49] H. Zhang, J. H. Shen, T. N. Zhang, \& Y. Li, "An improved chaotic particle swarm optimization and its application in investment", in the International Symposium on Computational Intelligence and Design (ISCID), Wuhan, China, 17-18 October 2008.

[50] H. J. Witthoft, Container: The megacarrier come. Hamburg: Charcoal burner, 2004.

[51] Hongkong International Terminals. "Our Operations. HIT: Hongkong International Terminals". 2007. Retrieved from http://www.hit.com.hk/4fac/key.asp\#CT

[52] G. Bakırl1, D. Birant, \& A. Kut, "An incremental genetic algorithm for classification and sensitivity analysis of its parameters". Expert Systems with Applications, Vol. 38, No. 3, 2011, pp. 2609-2620.

[53] J. J. Grefenstette, "Optimization of control parameters for genetic algorithms". IEEE Transactions on Systems, Man, and Cybernetics, Vol. 16, No. 1, 1986, pp. 122-128.

[54] M. Srinivas, \& L. M. Patnaik, "Genetic algorithms: a survey". Computer, Vol. 27, No. 6, 1994, pp. 17-26.

[55] K. T. Park, K. H. Kim, "Berth scheduling for container terminals by using a sub-gradient optimization technique". Journal of the Operational Research Society, Vol. 53, No. 9, 2002, pp. 1054-1062.

[56] K. H. Kim, \& K. C. Moon, "Berth scheduling by simulated annealing". Transportation Research Part B, Vol. 37, No. 6, 2003, pp. 541-560. 